\title{
Beyond the disorder: one parent's reflection on genetic counselling
}

\author{
Ruth McGowan Melbourne, Australia
}

\begin{abstract}
As a mother of two sons with adrenoleukodystrophy the author of this paper writes about her experiences of genetic counselling following the diagnosis. She discusses the dilemmas, emotions and aftermath this knowledge has brought to her family and the roles she played. Personal concerns are raised about the values guiding genetic counselling which, she found, focused on the technical details without considering the ethical implications arising from the new knowledge or the emotional dilemmas of prenatal testing. Some consequences of choice and the value of hope are discussed. She concludes by challenging genetic counsellors to deliver a service which not only provides technical information but is cognisant of the ethical considerations this information may foist upon a family.
\end{abstract}

(Fournal of Medical Ethics 1999;25:195-199)

Keywords: Adrenoleukodystrophy; genetic counselling; Lorenzo's Oil; children; therapy

"Mummy, if you're really special God picks you to have ALD!" my little boy said after I had just explained that some people are special and have to eat different food from others. I thought about this as I made the daily medicine milkshakes containing "Lorenzo's Oil" for my two sons, aged three and five. The boys drank them quickly and then ran outside to play - they looked so normal but so special too. Two of my three sons have adrenoleukodystrophy (ALD), an hereditary condition depicted in the 1992 film Lorenzo's Oil. ${ }^{1}$ We now take nothing for granted, such as the simple hopes that our sons will become teenagers or adult men.

Until the beginning of 1998, our lives had been blissfully ignorant of the genetic time bomb I am carrying but now we live in the shadow of never quite knowing when it may go off. There had been no previous diagnosis of ALD within my immediate or extended family. It is X-linked, can affect the central nervous system white matter and adrenal cortex, and is associated with the build up of very-long-chain fatty acids (VLCFA) due to the impaired ability to degrade these substances. ${ }^{2}$ Phenotype cannot be predicted and ranges from the childhood cerebral form (usually fatal), to the adult form adrenomyeloneurophy (AMN) which progressively affects the spinal cord. ${ }^{3}$ So far my sons remain neurologically normal, although it seems that about one third of boys with the gene will die as a result of progressive neurological damage before they are teenagers. In this article I discuss some of the impacts finding out about all this has had on my family, identify gaps in aspects of the genetic counselling I received and suggest how this service could be improved. I do not presume to speak for other families affected by ALD: their stories are too personal and individual for that.

In the past year my husband and I have met many dedicated and well-intentioned health care professionals through both the genetic counselling service and our subsequent efforts to know more about therapeutic options available for ALD. Through all these experiences my sons received a high standard of care from the many professionals involved. However, in facing the prospect of a serious hereditary disease and the personal ethical issues invariably raised, I have found myself with many questions but few answers. As a lay person untrained in ethical analysis, thinking about the ethics of my situation feels like trying to catch a slippery fish: just when I think I've caught it, it slips away. When I talked about ethical aspects of gene technology with family and friends some felt threatened by the topic as if by talking about it, I was being critical of their values or decisions. Others were wary of offending me and so did not wish to discuss the issue at all. I feel that genetic counsellors have a responsibility to discuss the ethical implications of the advice they provide to clients; if they don't, who will? To ignore this aspect as the unglamorous side of a hi-tech science, does not do justice to the complex issues gene-identifying technology brings to people's lives.

\section{Finding out}

December 1997, my five-year-old son was diagnosed with Addison's disease, which finally explained why in the previous 12 months he had 
suffered from severe gastroenteritis, requiring three hospital admissions. I did not know then that adrenal insufficiency is often associated with ALD. After this initial diagnosis my husband and I were adjusting to the fact that our son would be on steroid-replacement medication for life when we received a disturbing phone call from an endocrinologist to come in and discuss some test results. We were also advised that an appointment had been arranged for us to see the genetic counselling unit; an off-hand remark that filled me with foreboding. Following the shattering news that our eldest son had ALD our adjustment began to the possible impacts of this condition on my family. We struggled to deal with the questions raised by ourselves and others about ALD while at the same time trying to maintain relatively normal lives by keeping the terrible news in perspective. It was three more weeks before we were scheduled to see the genetic counselling service. Three long weeks of hell, waiting to find out the terms of our sentence and wondering if either of my two younger sons carried the gene for ALD, barely sleeping or eating and fearful whenever one of my children tumbled in the yard-was the fall because of normal childhood clumsiness or "it"? The fear and grief was at times overwhelming. In the meantime we had passed on the news about my son to family and relatives. A cousin of mine who was 19 weeks pregnant was able, through another hospital, to get testing immediately to determine her carrier status, which implied to me that a pregnant women has greater access to medical information than a distraught mother of two unconfirmed sons who are very much alive. While I am sure that genetic counselling services have to prioritise appointments, a compassionate service should try to fit in new clients as soon as possible after the initial diagnosis of an inherited condition, preferably within a week.

\section{Experiences of genetic counselling}

Reflecting on my experience as a client of genetic counselling I found the service could be more aptly named a genetic information service rather than genetic counselling, which tends to have connotations of compassion in today's therapyfocused world. The counselling aspects of dealing with the grief, anger and how to cope were secondary to the emphasis on the information, which covered genetic theory on X-linked inheritance, prenatal testing for termination of an affected fetus and who in my family would be at risk. Genetic counselling was useful in that I found out more about ALD and had some of my questions answered. However, I was left to cope with other issues resulting from this knowledge with little warning of what to expect, and litthe assistance and advice. Complex issues were either not discussed or sidelined, in a service thêt seemed to value choice as the guiding principle $\overrightarrow{\mathrm{t}_{0}}$ the exclusion of a frank discussion of the possibffe consequences of this right.

I went to the genetic counsellor with three man roles: I was a mother, a messenger-to-be of b news for my family and relatives, and a carrier $\frac{0}{9} \mathrm{f}$ ALD. Let me give some examples of how with hindsight, I feel these roles could have been better addressed.

As a mother I wanted the ALD status of ny other two sons established. Blood tests taken the first appointment confirmed that my three year-old-son had ALD and Addison's and rify baby was fine. This information was life-saving as it meant my son could now also begin treatmest for his Addison's disease and avoid the possibiligy that a future Addisonian crisis would not be treated.

The genetic counsellor also discussed prenal screening and other options for pregnant carriebs of ALD that would allow choice. Listening to thess information I received the impression that if I wass pregnant I would be advised to use this techno ogy. The value of choice inherent in prena商 screening is good for some and indeed welcomed but this key aspect of genetic counselling was immediately going to make my life any easier and as a mother this choice challenges the loyalty I fegl towards my sons. I do not plan to become pregnant again as I cannot imagine taking the pawh offered by prenatal screening. I would find extremely difficult to terminate an ALD-affectêd pregnancy and to separate that decision from rig love for my sons with ALD. After listening to genetic counsellor explain prenatal screening, I also think only a very brave parent woufd knowingly choose to bring a child with a flawed gene into the world.

\section{Family reactions}

As the bearer of bad news the onus was on me inform others who might be affected. Thiss involved providing them with the news about roy sons' diagnosis and answering their questions about ALD; a difficult task while adjusting to the impact of the devastating news for my immediate family. It would have helped if the genetic counsellor had given me an authoritative letter give to people about ALD, which included detaqs on how to contact a local genetic counsellor. SorBe of my siblings and relatives wanted to kn बiv immediately if they could get tested for ALD and asked me about carrier testing and options for prenatal screening. Others followed my news 
with a visit to a genetic counsellor. While acknowledging that my female relations have a right to access technology in order to make an informed choice, it was upsetting to be in the position of having to explain that they could choose to terminate an ALD-affected pregnancy. I answered their questions by explaining what I had heard from the genetic counsellor about prenatal testing options but all I could think of was "they want to know how to stop babies like my sons from being born". When I raised my ambivalence about a possible consequence of choice and the link to what it says about my sons, the genetic counsellor suggested I must "learn to separate the issues". It is extremely difficult for me to learn how to do this and I would have liked the genetic counsellor to have acknowledged this dilemma, and to have taught me me some skills to deal with it.

The diagnosis of an inherited condition can drop a bombshell into family relationships. I wish I had been given information on what to expect and advice on how to handle the various reactions of my relatives and siblings. Some of my siblings have chosen not to be tested to determine their carrier status. This reaction must be common in the experiences of genetic counsellors. I am worried for my sisters who remain untested and their young children but I am unsure how to approach this sensitive issue with them. I also don't know how explicit to be in answering my nieces' and nephews' questions about ALD when their parent has chosen not to be tested. I respect the right of my siblings to refuse testing but I can't help feeling angry at their denial of the potential impact of ALD on their lives.

Ethical aspects inherent in the role of news bearer that should be acknowledged within the context of genetic counselling include issues such as the rights of my siblings and relatives to know that a potentially fatal gene mutation occurs in our gene pool. I believed that they all had a right to know, but if I had not told them, would a doctor disclose this information to a pregnant relative? Alternatively, would I be told if another carrier or affected child was identified within my pedigree if the person affected wanted to keep the information confidential? This information is relevant to determine if the gene I carry was a chance mutation (which seems to happen in a small percentage of people with ALD) or is part of the family pedigree. In my case where the diagnosis of ALD is fairly recent, the exact mechanism of inheritance has not yet been established, with only my identical twin being confirmed as a carrier so far.
My third role, as a carrier who could possibly suffer health problems from ALD, was not addressed by the genetic counsellor. Although the risk of a carrier of the ALD gene suffering some neurological involvement is low, it can impact later in life. In fact, I have met two women carriers who are confined to wheel-chairs and another who has constant pain in her legs and back. Perhaps this risk was unknown or was seen as too low to address, or maybe it was avoided because the priorities of genetic counselling lie with prevention?

As a carrier I feel some guilt for having passed on this condition to my sons. I fear having to nurse my sons through slow, painful deaths from something I gave them, albeit unintentionally. This fear is leading me to try and do everything I can for them-within limits. Bone-marrow transplants are a risky but possible therapy option for my sons if they became symptomatic. Both my affected sons have identical bone-marrow types but there is no other match within the family, reducing the odds of a successful transplant. People have asked me if I would consider having in vitro fertilisation (IVF) and selecting a female embryo, with the chance of finding a sibling bone-marrow match for my sons. At this stage, my husband and I have rejected such options as we feel it is not right for us to have a child for such reasons. I hope I won't regret this decision but I really believe that people should be valued for more than just their genes.

\section{An ideal service}

Genetic counselling sells itself as a service that provides information so that people can make an informed choice. Ideally, the genetic counsellors would realise that the situation is more complex than this, and would provide their service in a way that recognises the many roles of a client and helps them develop skills to meet the needs of these roles. For example, advice on how to explain the news to children in a way which doesn't frighten them, and which makes them feel special, would be greatly appreciated by parents; this is something it is important for them to learn. In this way, positive, practical skills can be taken home and applied once a session is over. As a client of genetic counselling I found the emphasis of the relationship was more on what was wrong within a family (the heritable gene) rather than on what is right (my parenting skills). Perhaps this is understandable, given the reason I was seeing a genetic counsellor was to discuss ALD. But this negative focus fuelled my fear as I tried to survive those months following the diagnosis. An ideal service would shift this emphasis from the genetic flaw by also valuing what is right about the parenting and 
by giving positive feedback on how the family is adjusting to the news.

\section{Consequence of choice}

There are consequences of gene technology beyond that of allowing people more choice, but these are rarely discussed by the popular media or in handout material provided by genetic counselling services. For me one of the applications of this technology to ALD is that questions about possible quality of life become secondary to identification of the gene. With ALD, phenotypic variability means the decision to terminate a pregnancy is difficult and certainly not clear-cut, unlike perhaps other inherited conditions whereby the correlation of genotype and phenotype is established. There is currently no way of knowing what phenotype may be expressed within a family that has ALD and two brothers with the gene can be affected very differently. In fact, a small percentage of males can develop the Addison's only or asymptomatic phenotype and live long, productive and happy lives. Adrenomyeloneurophy (AMN), the most common phenotype, does not usually manifest until adulthood, with some men surviving to the eighth or even the ninth decade with families, jobs and children. There is something about this technology which unsettles me in that it can reduce a potential human being to one part rather than focusing on the total sum of those parts. This feeling mirrors the concern I have when my boys are labelled as dis-orders, without their other special qualities being recognised.

\section{Use of language}

One of the questions we were asked in our first genetic counselling session was about the type of contraception we were using. This question was asked, assuming that my husband and I had not thought about this issue - of course it was a prime consideration. Personal questions of this nature, didn't seem to be relevant to the treatment of my sons and indeed, made me feel defensive of our parenting abilities. This transaction seemed to insinuate that we should be using something to prevent more mutations from being born and made me feel embarrassed and ashamed of our joyful capacity to bring children into the world. This is not just an issue of semantics: the way such a question is asked typifies the paradigm of genetic counselling which seems to emphasise prevention (the genetics) rather than the compassionate (counselling) aspects.

I felt that some of the language used by health care professionals objectified my sons by classifying them as unfortunate case studies or freaks, instead of real people. This feeling was exacerbated by the terminology used to describe ALD, which does recognise that there is so much more order than disorder in my son's lives. For instance, the ter $\vec{m}$ s genetic disorder and inborn errors of metabolism are accepted medical terms. While I do recognise that other families may prefer these common terms $\overline{\overline{s e}}$ I found the language to be negative, blaming afg insulting. These are not words with positive conromtations and in fact define my boys, my beautiful playful sons, by a problem, a dis-order. They are healthy and "normal" now, which is not to deny tre seriousness of what could happen. Labels illustrae a value judgment which can be unhelpful or help to clients and their families. For example, health professionals would not call an overweight, middfs aged businessman "Mr-Heart-Attack-Waiting-teHappen". Today, those living with HIV are co longer called "AIDS sufferers"; a change $̧ \mathrm{ff}$ language that recognises courage and provides hope.

\section{The value of hope}

Hope is uplifting and valuable when all around is uncertain for without hope the alternative for toe would be despair. In my experience, genetuc counselling on ALD confines discussion of hope to the technology of prenatal and carrier screeniof but these scientific advances are not, by their nature, promising for my sons. For me gene testing is a double-edged sword which simultaneously promises so much but delivers so little, p ticularly when a positive test result solves

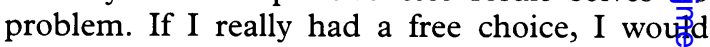
choose a technology which cures ALD, not prevents and I am heartened by the promising advances in fields such as gene therapy which mây benefit my sons in their lifetime.

I would like the health care professionals I de्gुl with also to have hope for my sons as that is important basis for a trusting relationship. Afer talking to a range of doctors and reading the literature on ALD the choice my family has made is to try the still experimental therapy of Lorenz\&s Oil combined with a diet restricted in fats. TKis choice has led to the medicalisation of my children but we feel it is better to take this chance than nothing and they are regularly monitored $\Phi_{0}$ ensure it is not harming them.

\section{Help the medicine go down}

Genetic counselling provided me with infor mation that was interesting and useful but it coufd have done more. As a trained scientist I know hog easy it is to define information in terms of ta technical language of research results, analysis a 
probabilities but the values and objectivity of science are of little use to me in facing the ethical issues raised by the diagnosis of my sons and the implications for family relationships. The challenge for genetic counsellors is to focus beyond the science to provide a service which acknowledges and responds to the ethical dilemmas raised and takes on the responsibility of working with the client in dealing with the consequences of this information. This will require skilled health care professionals who are cognisant of the ethical and emotional implications of their work and trained in discussing these issues, just as they are currently trained in providing the technical information. Maybe I am expecting too much from one professional and perhaps my ideal already exists in other genetic counselling services. But, then againmaybe ethics is the fish that always gets away.

I could never have imagined what it would be like to experience the diagnosis of a serious genetic condition within my family. I thought those sort of things always happened to other people and with the distribution of ALD within a population being well over 100,000 to one, it usually does. Perhaps it is difficult to empathise with my experiences but I hope that by voicing my story, understanding can increase about some of the dilemmas parents may face as clients of genetic counselling long after an appointment is over.

For now, life is good and the sun is shining. I can hear my boys playing happily outside in the
Spring afternoon, oblivious to the shadow of ALD that echoes through our days. In the absence of a definite cure for the condition my boys have, choices are valuable but they don't make life any easier. If you came to our house and made the medicine milkshakes you would see little boys not disorders. My sons are special people, beyond their genetic flaw and it is love not science that puts meaning in our lives.

\section{Acknowledgement}

The author wishes to acknowledge the support of Associate Professor Julian Savulescu, Director of the Ethics Programme at The Murdoch Institute, the Royal Children's Hospital, Melbourne Australia for assistance in preparing this article for publication.

Ruth McGowan BAgriSci, MApplSci, has three sons: two have adrenoleukodystrophy. email: ruthmcg@ hotmail.com

\section{References and notes}

1 Lorenzo's Oil, a film directed by George Miller, starring Nick Nolte and Susan Sarandon, 1992, and made at Universal City Studios.

2 Moser HW. Adrenoleukodystrophy: phenotype, genetics, pathogenesis and therapy. Brain 1997;120:1485-1508.

3 Bezman L, Moser HW. Incidence of X-Linked adrenoleukodystrophy and the relative frequency of its phenotypes. American fournal of Medical Genetics 1998;76:415-19. 